\title{
A case of blood chimerism and twin-to-twin transfusion syndrome in monochorionic dizygotic twins
}

Silvia Marin ${ }^{1}$, Sara Fernandez ${ }^{1}$, Antolin Alvarado Eugenia ${ }^{1 *}$, Carmina Bermejo ${ }^{1}$, Pilar Martinez-Ten ${ }^{2}$, Elena Mansilla ${ }^{3}$, Maria de la Calle ${ }^{1}$, Roberto Rodriguez ${ }^{1}$, Beatriz Herrero ${ }^{1}$, Laura Sotillo ${ }^{1}$, Francisco Lopez ${ }^{1}$, Fe Garcia ${ }^{3}$ and Jose Luis Bartha ${ }^{1}$

${ }^{1}$ Fetal Medicine Department, Obstetrics and Gynecology Unit, La Paz Hospital, Madrid, Spain

${ }^{2}$ Delta Clinic, Imaging Diagnosis Center in Obstetrics and Gynecology, Madrid, Spain

${ }^{3}$ Medical and Molecular Genetics Institute (INGEMM), La Paz Hospital, IdiPAZ, UAM y CIBERER, ISCIII, Madrid, Spain

\section{Introduction}

Monochorionic (MC) twins have been usually considered genetically identical as they developed from a single initial embryo which suffers a cleavage after the fourth day of conception. However, this concept was challenged by several reports of sex-discordant MC twins that could only be explained by dizygosity [1-13]. A recently systematic review by Peters, et al. finds 31 cases of MCDZ since 2000 to nowadays [14].

These twins may demonstrate mixed blood karyotypes from both twins being discordant for their phenotype, but also an atypical case of solid chimeric organ genotype has been described [13]. Although some cases have been reported by spontaneous conception [12,13], the majority of these pregnancies were achieved by assisted reproductive technology (ART), which might affect some qualities of the embryo.

Monochorionic twin pregnancies are related to higher risk of fetal complications owing to placental vascular anastomoses. One of the most important is twin-to-twin transfusion syndrome (TTTS) that occurs in $10 \%$ of MC pregnancies [15]. Unbalanced blood flow through inter-twin vascular connections results in a net unidirectional flow from one twin to the other. In these pregnancies, an intensive surveillance, extensive counseling as well as management options should be provided.

\section{Case report}

We report the case of a 37-year-old healthy primigravida woman who conceived through ART. Her own oocytes were fertilized using intracytoplasmic sperm injection (ICSI), obtaining two goodquality embryos that were transferred into the uterus. Ultrasound (US) scan at 6.0 weeks of pregnancy revealed a MC diamniotic twin pregnancy. Because a discordant genital sex was observed at 15 weeks of pregnancy, an amniocentesis of both sacs was performed. QF-PCR technique showed a monosomic pattern for chromosomes $\mathrm{X}$ and $\mathrm{Y}$ in the genital male fetus (twin 1) and a disomic pattern for chromosome $\mathrm{X}$ and a nulisomic pattern for chromosome $\mathrm{Y}$ in the genital female fetus (twin 2) (Figure 1). Karyotypes were 46, XY and 46, XX for the genital male fetus and the genital female fetus, respectively. Study of zygosity confirmed dizygosity. The diagnosis of a MC dizygotic (MCDZ) twin was then established, and as a high-risk pregnancy, the patient was scanned every 2 weeks.

At 24 weeks, because a discordant amniotic fluid volume was detected, the patient was referred to our center. Our initial US assessment confirmed a twin gestation with a thin dividing membrane with T-shaped insertion into the placenta and a marginal placental cord insertion of first twin and a velamentous placental cord insertion of second one (Figure 2). Twin 1 had an estimated fetal weight of 761 g (p 47.7), normal amniotic fluid (MVP $8 \mathrm{~cm}$ ), normal Doppler study, and visible bladder. Twin 2 had an estimated fetal weight of $627 \mathrm{~g}(\mathrm{p}$ 11.5), normal amniotic fluid (MVP $4 \mathrm{~cm}$ ), normal Doppler study, and a present bladder. Therefore, both biometric discordance of $19 \%$ and amniotic fluid discordance were observed, with no TTTS criteria. A close US surveillance was performed weekly in order to establish an early diagnosis of TTTS.

US findings remained steady until 28.5 weeks of gestation, when a diagnosis of TTTS III stage was established. Cervical length was of $23 \mathrm{~mm}$. The patient was admitted to hospital, and betamethasone was administered to get lung maturation. The case was discussed, and two options were contemplated: amnioreduction versus laser of placental vascular anastomosis. Because of the advanced gestational age, amnioreduction was decided in order to wait for betamethasone effects. An amnioreduction of $2500 \mathrm{cc}$ of amniotic fluid from the sac of recipient twin was carried out. Ultrasound findings persisted $24 \mathrm{~h}$ later; thus, a cesarean section was indicated.

The infants were delivered by an uncomplicated cesarean section at 28.6 weeks. Twin 1 (recipient) was a phenotypically healthy boy, without hydropic signs, with birthweight $1131 \mathrm{~g}$, Apgar test of 5/7, hemoglobin $19.3 \mathrm{~g} / \mathrm{dL}$, and hematocrit 59\%, and twin 2 (donor) was a phenotypically a healthy girl with birthweight $887 \mathrm{~g}$, Apgar test of 6/8, hemoglobin $19 \mathrm{~g} / \mathrm{dL}$, and hematocrit $58.1 \%$.

The histologic study of the placenta confirmed a MC diamniotic twin placenta. The genetic study of two sections of the placenta confirmed two different cellular lines, predominantly male component (2:1). Cytogenetic analysis of blood lymphocytes by QF-PCR technique obtained at 2 days of age showed that both infants had two cellular lines coming from different zygotes. Both twins were found to have a cell line proportion of 8:1 XY/XX confirming a blood chimerism.

${ }^{*}$ Correspondence to: Antolin Alvarado Eugenia, Fetal Medicine Department, Obstetrics and Gynecology Unit, La Paz Hospital, Madrid, Spain, E-mail: eantolin@salud.madrid.org

Key words: blood chimerism, monochorionic dizygotic, twins, twin-to-twin transfusion syndrome

Received: January 05, 2019; Accepted: January 15, 2020; Published: January 20, 2020 

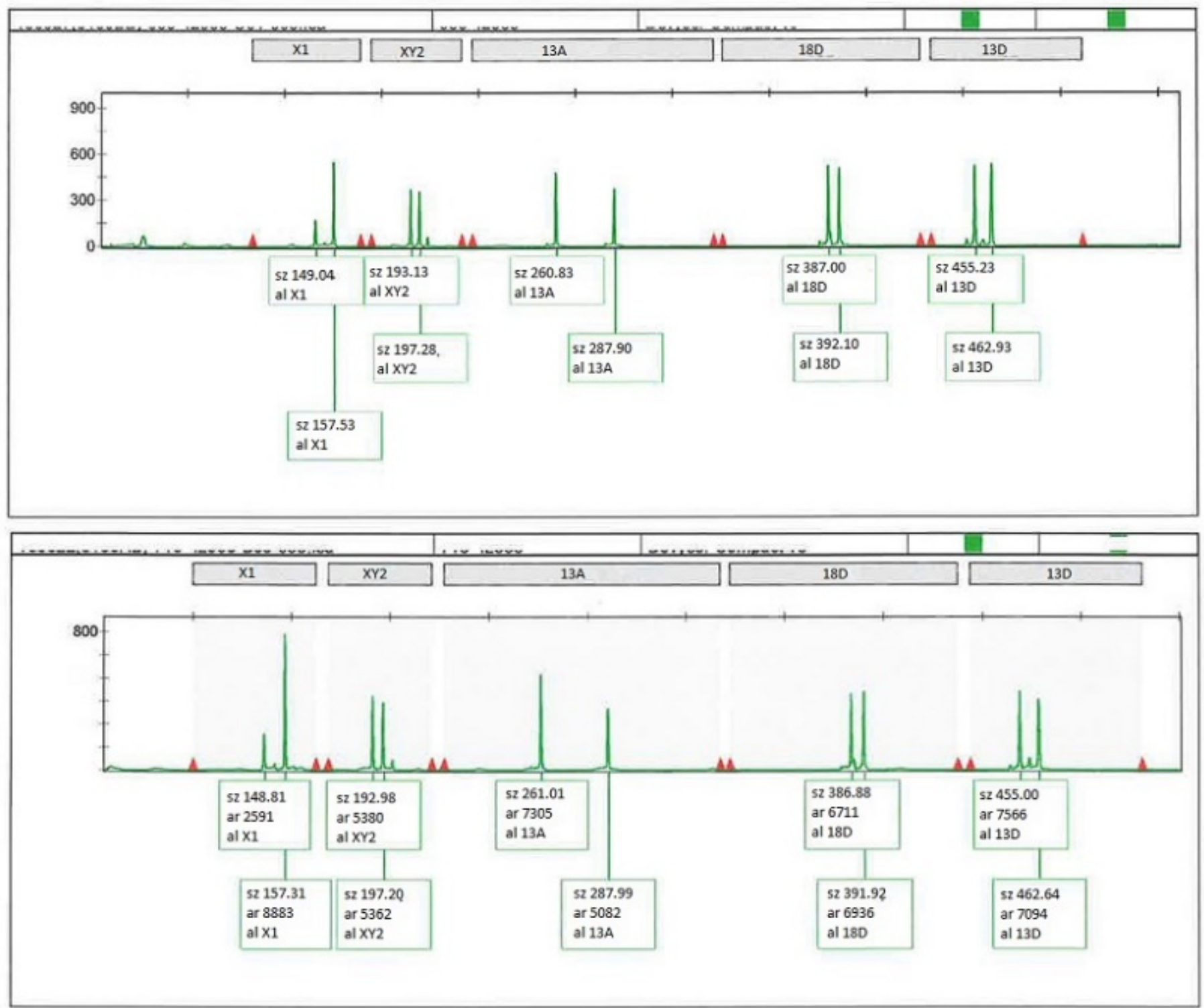

Figure 1. QF-PCR analysis of blood from twin 1 (recipient, boy) and twin 2 (donor, girl)

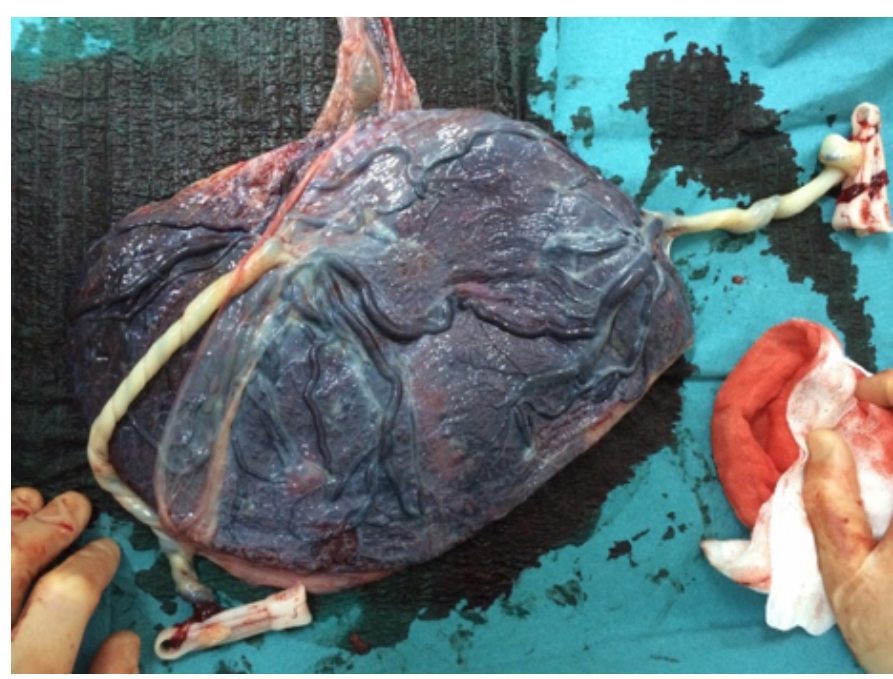

Figure 2. Placenta

\section{Discussion}

Although all MC twins are expected to be monozygotic, MCDZ twins have been reported, with mixed blood karyotypes and even solid tissue chimerism in some of them, such as buccal and skin chimerism $[13,14]$. Many hypotheses try to explain these MCDZ twin pregnancies.

These twin pregnancies are considered to be exceptional although there are progressively more cases reported to date [1-14]. Several theories try to explain their origin. Miura and Niikawa proposed that two separate embryos fuse their outer cell mass at late morula stage before the implantation; thus, both of them are surrounded by a single trophoblast, a mechanism also called "embryo amalgamation" $[13,16]$. Other hypothesis includes binovular follicle fertilization, in which two oocytes are presented with a single zona pellucid and the unusual fertilization of the second polar body by sperm with a different sex chromosome [4].

The fact that these pregnancies are commonly associated with ART can be explained by different mechanisms which may increase the 
possibilities of cell fusion. They include simultaneous embryo transfer at close sites into the utero, assisted hatching by disrupting of the zona pellucida, the transfer in blastocyst stage, and different cell culture conditions that may lead to change the cell surface $[15,17]$. However, there are some reported cases of spontaneous MD twins too, although the exact mechanism by which they occur remains unclear [13].

Chorionicity must be determined between 11.0 and 13.6 weeks of gestation using the membrane thickness at the site of insertion into the placenta by ultrasound $[18,19]$. Monochorionic twins are diagnosed by the T-sign of the membrane. When a discordant genital sex is suspected by US in a MC twin, two are the main causes: heterokaryotypic MZ twins (usually due to a postzygotic loss of the Y-chromosome in one twin) and MCDZ twins. Zigosity studies are needed in order to differentiate them.

Currently, confined blood chimerism has been described in most cases of MCDZ twins. It could be explained by the exchange of blood cells through the vascular anastomoses presented in a MC placenta [7]. This chimerism would persist in extrauterine life due to immunotolerance that has been created during fetal life [12]. However, there are few reported cases of sex-discordant MCDZ twins with chimeric karyotype in other tissues such as skin or buccal epithelium $[13,14]$, and then, the mechanism previously proposed does not seem to be plausible [13]. Fumoto, et al. proposed two explanations, the first one, an ectopic differentiation of chimeric hematopoietic stem cells; and the other one, the chimera is generated at an early stage of embryogenesis [14,20]. Although several cases of confined blood chimerism have been reported, there are no data of the implications that this would entail. In theory, this chimerism would not show sexual development impairment [2,3]; however, a case of testicular hypoplasia has been described in a MCDZ twin in which no other justifying cause was found [21]. It has also been postulated the association of this chimerism with impaired immunity, which may increase the risk of autoimmune diseases [11], but long-term studies are needed to clarify this point.

As perinatal outcome does not depend on zygosity but on chorionicity, MCDZ twins must be followed up as MC high-risk pregnancies with US scans every 2 weeks in order to rule out the main complications, TTTS, and selective intrauterine growth restriction. TTTS is a severe condition that can complicate $10 \%$ of MC pregnancies and results from uncompensated unidirectional blood flow between both twins through placental anastomoses [15]. There are several types of anastomoses but arteriovenous (AV) have an unidirectional flow, and thus, they are mainly responsible for this syndrome.

The perinatal outcome of MC pregnancies conceived by ART compared to spontaneous conception is an important issue. At this time, there are several reports supporting that ART increases the already high risk of MC pregnancies with increased preterm birth and low birthweight rates $[18,22]$. Regarding others complications, such as TTTS, few data have been reported to date: a retrospective study on 327 monochorionic pregnancies, where a significant decrease in the incidence of TTTS in MC pregnancies after IVF was objectivated [23]. The hypothesis proposed in this study is the differential MZ twinning process of ART pregnancies versus spontaneously conceived twins.

To our knowledge, only three other cases of MCDZ twin pregnancies complicated by TTTS have been reported $[1,8,24]$ (Table 1). Including our case, three of them were conceived by ICSI, supporting that ART may play an important role. All of them were diagnosed as MC twin pregnancy according to ultrasound findings at first trimester, objecting discordant sexes later. Due to discordant sexes, amniocentesis was performed in the case reported by Ekelund (case 2) and in our case, with $46, \mathrm{XX}$ and $46, \mathrm{XY}$ result for each sac. In case 2 , because zygocity testing showed that the fetuses were dizygotic, it was diagnosed as a DCDA pregnancy, probably inducing a delay on TTTS diagnosis until 32 weeks of gestation, when the cesarean section was performed. Furthermore, there is a remarkable finding, as in two of these cases and in our case the diagnosis of TTTS was upon 26 weeks, whereas this syndrome is usually described before. In the case reported by Ekelund, as previously mentioned, the diagnosis at 32 weeks could be due to the fact that, after amniocentesis, a DCDA gestation was considered. However, in the case reported by Assaf (case 3) and in our case, the ultrasound assessment was considering MC pregnancy, with TTTS findings at 26 weeks of gestation in Assaf s case and at 28.0 weeks in

Table 1. Cases of MCDZ twin pregnancies complicated with twin to twin transfusion syndrome, including our case

\begin{tabular}{|c|c|c|c|c|}
\hline Cases & $\begin{array}{l}\text { 1.QUINTERO } \\
\text { 2003. (1) }\end{array}$ & $\begin{array}{l}\text { 2. EKELUND } \\
\text { 2008. (4) }\end{array}$ & 3.ASSAF. 2010 (9) & OUR CASE \\
\hline Art & No & ICSI & ICSI & ICSI \\
\hline First US diagnosis & $\begin{array}{l}\text { MCDA } \\
\text { (12 weeks) }\end{array}$ & $\begin{array}{l}\text { MCDA } \\
\text { (8 weeks) }\end{array}$ & MCDA & $\begin{array}{l}\text { MCDA } \\
\text { (8 weeks) }\end{array}$ \\
\hline Prenatal diagnosis of dizigosity & No & $\begin{array}{l}25 \text { weeks } \\
\text { Amniocentesis (46XX, } 46 \mathrm{XY}) \text {. } \\
\text { Dizygotic }\end{array}$ & $\begin{array}{l}26 \text { weeks } \\
\text { Amniocentesis } \\
\text { (during TTTS treatment) } \\
46 \mathrm{XY} \text { (only recipient sac) } \\
\text { No zygocity testing }\end{array}$ & $\begin{array}{l}15 \text { weeks } \\
\text { Amniocentesis } \\
46 X X, 46 X Y \\
\text { Dizygotic }\end{array}$ \\
\hline TTTS diagnosis & $18+1$ weeks & 32 weeks & 26 weeks & $28+5$ weeks \\
\hline TTTS treatment & $\begin{array}{l}18+4 \\
\text { Fetoscopic Laser }\end{array}$ & No & $\begin{array}{l}26 \\
\text { Fetoscopic Laser }\end{array}$ & $\begin{array}{l}28+5 \\
\text { Amniorreduction }\end{array}$ \\
\hline GA AT delivery & Miscarriage (19 weeks) & 32 weeks & $37+4$ weeks & $28+6$ weeks \\
\hline Type of delivery & - & Caesarean section & Caesarean section & Caesarean section \\
\hline $\begin{array}{l}\text { Weight } \\
\mathrm{Hb}\end{array}$ & - & $\begin{array}{l}\text { A: Male, } 2265 \mathrm{~g}, \mathrm{Hb} 14.6 \mathrm{~g} / \mathrm{dL} \\
\text { B: Female, } 1550 \mathrm{~g}, \\
\mathrm{Hb} 7.4 \mathrm{~g} / \mathrm{dL}\end{array}$ & $\begin{array}{l}\text { A: Male, } 2892 \mathrm{~g} \\
\text { B: Female, } 3487 \mathrm{~g}\end{array}$ & $\begin{array}{l}\text { A: Male, } 1131 \mathrm{~g}, \\
\mathrm{Hb} 19.3 \mathrm{~g} / \mathrm{dL} \\
\mathrm{B}: \text { Female, } 887 \mathrm{~g}, \\
\mathrm{Hb} 19 \mathrm{~g} / \mathrm{dL}\end{array}$ \\
\hline Placenta & MCDA & MCDA & MCDA & MCDA \\
\hline Genetics at birth & $\begin{array}{l}46 \mathrm{XX} \\
46 \mathrm{XY}\end{array}$ & $\begin{array}{l}\text { A: } 46 \mathrm{XX}[13] / 46 \mathrm{XY}[17] \\
\text { B: } 46 \mathrm{XX}[13] / 46 \mathrm{XY}[17]\end{array}$ & $\begin{array}{l}\text { A: } 46 \mathrm{XX}[32] / 46 \mathrm{XY}[28] \\
\text { B: } 46 \mathrm{XX}[73] / 46 \mathrm{XY}[27]\end{array}$ & $\begin{array}{l}\text { A: } 46 \mathrm{XY}[8] / 46 \mathrm{XX}[1] \\
\text { B: } 46 \mathrm{XY}[8] / 46 \mathrm{XX}[1]\end{array}$ \\
\hline $\begin{array}{l}\text { Long-term } \\
\text { Genetics }\end{array}$ & & $\begin{array}{l}3 \text { months: } \\
\text { A: } 46 \mathrm{XX}[5] / 46 \mathrm{XY}[6] \\
\text { B: } 46 \mathrm{XX}[6] / 46 \mathrm{XY}[6]\end{array}$ & $\begin{array}{l}9 \text { months: } \\
\text { A: } 46 \mathrm{XX}[174] / 46 \mathrm{XY}[126] \\
\text { B: } 46 \mathrm{XX}[180] / 46 \mathrm{XY}[120]\end{array}$ & \\
\hline
\end{tabular}


our case. Regarding the postnatal genetic study, in the case of Quintero, only a study of zygosity in the abortive material was carried out. In the other two cases, blood chimerism was objectified, which persisted at 6 and 9 months, respectively, without finding chimerism in buccal cells.

As regards the management of TTTS, fetoscopic laser photocoagulation of placental anastomoses is considered by most experts to be the best available approach for stages II, III, and IV TTTS in pregnancies before 26 weeks [15]. Some controversy exists regarding stage I, as no progression is described in more than $50 \%$ of cases with expectant management. In addition, the overall neonatal survival of at least 1 twin is higher when diagnosis is made upon 26 weeks [25]. Traditionally, after 26 weeks of gestation, less invasive treatments such as expectant management, amnioreduction, or preterm delivery are preferred $[26,27]$. However, recently, three studies reported better results when laser photocoagulation was performed $>26$ weeks of gestation compared with expectant management or amnioreduction [27-29]. In the pre- sent case, we decided amnioreduction in order to wait for pulmonary maturation and to finish the pregnancy due to the severity of Doppler findings and the advanced gestational age, obtaining two healthy newborns.

\section{Conclusion}

There are progressively more cases of MCDZ twins reported. Usually, the diagnosis comes after observing discordant sex in a MC pregnancy, so it may be an under- diagnosed of these types of twining and be more common than previously expected.

It is necessary to increase our knowledge about this mechanism of twinning to improve the management of these pregnancies, having in mind some MC complications, such as the development of TTTS in a more advanced gestational age than usual. Finally, we should learn about the long-term consequences of blood and tis- sue chimerism in these children.

\section{Conflict of interest}

None declared.

\section{References}

1. Quintero RA, Mueller OT, Martinez JM, Arroyo J, Gilbert-Barness E, et al. (2003) Twin-twin transfusion syndrome in a dizygotic monochorionic-diamniotic twin pregnancy. J Matern Fetal Neonatal Med 14: 279-281.

2. Souter VL, Kapur RP, Nyholt DR, Skogerboe K, Myerson D, et al. (2003) A report of dizygous monochorionic twins. N Engl J Med 349: 154-158.

3. Williams CA, Wallace MR, Drury KC, Kipersztok S, Edwards RK, et al. (2004) Blood lymphocyte chimerism associated with IVF and monochorionic dizygous twinning: case report. Hum Reprod 19: 2816-2821.

4. Ginsberg NA, Ginsberg S, Rechitsky S, Verlinsky Y (2005) Fusion as the etiology of chimerism in monochorionic dizygotic twins. Fetal Diagn Ther 20: 20-22.

5. Aoki R, Honma Y, Yada Y, Momoi MY, Iwamoto S (2005) Blood chimerism in monochorionic twins conceived by induced ovulation: case report. Hum Reprod 21 : 735-737.

6. Souter VL, Parisi MA, Nyholt DR, Kapur RP, Henders AK, et al. (2007) A case of true hermaphroditism reveals an unusual mechanism of twinning. Hum Genet 121: 179-185.

7. Walker SP, Meagher S, White SM (2007) Confined blood chimerism in monochorionic dizygous (MCDZ) twins. Prenat Diagn 27: 369-372.

8. Ekelund CK, Skibsted L, Søgaard K, Main KM, Dziegiel MH, et al. (2008) Dizygotic monochorionic twin pregnancy conceived following intracytoplasmic sperm injection treatment and complicated by twin-twin transfusion syndrome and blood chimerism. Ultrasound Obstet Gynecol 32: 832-834.

9. Hackmon R, Jormark S, Cheng V, O'Reilly Green C, Divon MY (2009) Monochorionic dizygotic twins in a spontaneous pregnancy: a rare case report. J Matern Fetal Neonatal Med 22: 708-710.
10. Hawcutt D, Hammond B, Sibbring J, Gokhale D, Ellis I, et al. (2011) Twin-twin confusion syndrome: Blood chimerism in opposite sex dizygotic twins. $J$ Obstet Gynaecol 31: 446-448.

11. Chen K, Chmait RH, Vanderbilt D, Wu S, Randolph L (2013) Chimerism in monochorionic dizygotic twins: case study and review. Am J Med Genet A 161: 1817 1824.

12. Kanda T, Ogawa M, Sato K (2013) Confined blood chimerism in monochorionic dizygotic twins conceived spontaneously. AJP Rep 3: 33-36.

13. Rodriguez-Buritica D, Rojnueangnit K, Messiaen LM, Mikhail FM, Robin NH (2015) Sex-discordant monochorionic twins with blood and tissue chimerism. Am J Med Genet A 167: 872-877.

14. Peters HE, König TE, Verhoeven MO, Schats R, Mijatovic V, et al. (2017) Unusual twinning resulting in chimerism: a systematic review on monochorionic dizygotic twins. Twin Res Hum Genet 20: 161-168.

15. Society for Maternal-Fetal Medicine, Simpson LL (2013) Twin-twin transfusion syndrome. Am J Obstet Gynecol 208: 3-18.

16. Miura K, Niikawa N (2005) Do monochorionic dizygotic twins increase after pregnancy by assisted reproductive technology? J Hum Genet 50: 1-6.

17. Boklage CE (2005) Embryogenesis of chimeras, twins and anterior midline asymmetries. Hum Reprod 21: 579-591.

18. Simoes T, Queirós A, Marujo AT, Valdoleiros S, Silva P, et al. (2015) Outcome of monochorionic twins conceived by assisted reproduction. Fertil Steril 104: 629-632.

19. Khalil A, Rodgers M, Baschat A, Bhide A, Gratacos E, et al. (2016) ISUOG Practice Guidelines: role of ultrasound in twin pregnancy. Ultrasound Obstet Gynecol 47: 247263.

20. Fumoto S, Hosoi K, Ohnishi H, Hoshina H, Yan K, et al. (2014) Chimerism of buccal membrane cells in a monochorionic dizygotic twin. Pediatrics 133: e1097-1100.

21. Choi DH, Kwon H, Lee SD, Moon MJ, Yoo EG, et al. (2013) Testicular hypoplasia in monochorionic dizygous twin with confined blood chimerism. $J$ Assist Reprod Genet 30: 1487-1491.

22. Zhao DP, Cambiaso O, Otaño L, Lewi L, Deprest J, et al. (2015) Veno-venous anastomoses in twin-twin transfusion syndrome: A multicenter study. Placenta 36: 911-914.

23. Ben-Ami I, Molina FS, Battino S, Daniel-Spiegel E, Melcer Y, et al. (2016) Monochorionic diamniotic in vitro fertilization twins have a decreased incidence of twin-to-twin transfusion syndrome. Fertil Steril 105: 729-733.

24. Assaf SA, Randolph LM, Benirschke K, Wu S, Samadi R, et al. (2010) Discordant blood chimerism in dizygotic monochorionic laser-treated twin-twin transfusion syndrome. Obstet Gynecol 116: 483-485.

25. Duryea EL, Happe SK, McIntire DD, Dashe JS (2016) The natural history of twin-twin transfusion syndrome stratified by Quintero stage. J Matern Fetal Neonatal Med 29 3411-3415.

26. Kuller J, Norton M (2013) Expanding the gestational age limits for laser treatment for twin-twin transfusion. Am J Obstet Gynecol 208: 165-166.

27. Baud D, Windrim R, Keunen J, Kelly EN, Shah P, et al. (2013) Fetoscopic laser therapy for twin-twin transfusion syndrome before 17 and after 26 weeks' gestation. $\mathrm{Am} \mathrm{J}$ Obstet Gynecol 208: 197-e1.

28. Middeldorp JM, Lopriore E, Sueters M, Klumper FJ, Kanhai HH, et al. (2007) Twinto-twin transfusion syndrome after 26 weeks of gestation: is there a role for fetoscopic laser surgery? BJOG 114: 694-698.

29. Valsky DV, Eixarch E, Martinez-Crespo JM, Acosta ER, Lewi L, et al. (2012) Fetoscopic laser surgery for twin-to-twin transfusion syndrome after 26 weeks of gestation. Fetal Diagn Ther 31: 30-34.

Copyright: (C2020 Marin S. This is an open-access article distributed under the terms of the Creative Commons Attribution License, which permits unrestricted use, distribution, and reproduction in any medium, provided the original author and source are credited. 